\title{
Joining Together to Alleviate the Burdens of Cancer
}

\author{
Joseph O'Donnell
}

Published online: 25 August 2010

(C) Springer 2010

Welcome to volume 25, issue 3 of the Journal of Cancer Education - our third with our new publisher, Springer. We are deeply indebted to them for all they have done to help us with our backlog, get accepted articles up online as quickly as possible, help modernize and streamline the submission and review process, and all in all, for being very supportive and helpful partners in the growth of the journal, the AACE, the EACE, and CPEN.

We are experiencing a record number of submissions and although I haven't gotten all the bugs quite worked out yet, the processes seem more manageable, and I promise they will get better.

You receive this issue at the time of the 2010 annual AACE/CPEN/EACE meeting in beautiful San Diego, where we will focus on The Impact of Cancer Education on Patients, Practitioners and the Public. Have a look at the abstracts-and turn them into articles! Use the articles for ideas to improve cancer education and cancer outcomes in your locale!

This San Diego meeting will be the third joint endeavor with AACE, EACE, and CPEN. The wealth of talent and ideas and good people doing good things is a treasure for all of us! If you can't come to San Diego, mark down Buffalo for the fall of 2011 and Nicosia, Cyprus for an unforgettable EACE meeting in March 2011.

Just as Springer has been very helpful in getting our act together for the journal, the leadership group of AACE, and especially the indomitable Frank Ferris with executive secretary Paula Frampton Brown at his side, have been pushing AACE to new clarity, purpose, and value for members. Frank, with the help of others, has redone the

J. O’Donnell $(\bowtie)$

Dartmouth Medical School,

Hanover, NH, USA

e-mail: Joseph.F.ODonnell@Dartmouth.EDU website - I urge you to visit it at http://www.aaceonline. com. He led us to develop a new mission and vision statement, which I include:

The Mission of AACE To promote accurate, effective, and focused cancer education by those responsible for the education of health professionals, patients, families, caregivers, survivors, and the public. The Association serves as a forum for the advocacy, scientific investigation, development, evaluation, reporting, and dissemination of information relevant to this mission.

The Vision of AACE Elimination of the burden of suffering from cancer in the world through education.

The Core Values of AACE Accuracy of message, effective interchange of knowledge, rigorous evaluation methods, cultural sensitivity, respect for the audience, professional development, and mentorship.

Goal Develop a community of cancer educators.

The Association provides a forum for health-related professionals concerned with the study and improvement of cancer education at the undergraduate, graduate, continuing professional, and paraprofessional levels. Active members include physicians, dentists, nurses, health educators, social workers, occupational therapists, and other professionals interested in cancer education. Cancer education efforts are related to prevention, early detection, treatment, and rehabilitation. Other interests of the Association include educational programs for the general public, for populations at special risk, and for cancer patients. Such efforts involve developing and evaluating new educational strategies and methods, including the examination of objectives, courses, 
and evaluation instruments; expanding public education; fostering international cooperative efforts in cancer education; and furthering education in cancer prevention.

The core products of the AACE that supply the value in membership include:

1) The annual meeting, which provides a chance to network with like-minded colleagues, and also a chance to present good work and find mentorship, collaboration, validation and constructive critique, and connection with funders.

2) This journal, which offers a chance to publish, learn, and help move the field forward.

3) Our website, which provides a connection with educational resources and

4) An organization that can help foster one's career and aspirations, which in turn can lead to more success in alleviating the burden of suffering from cancer. We want to leave the world a better and healthier place!

Our sister organization, the European Association for Cancer Education (EACE), has as its aim "to improve clinical outcomes through the education and training of individuals involved within the cancer and palliative care continuum and to facilitate communication and networking between those involved in cancer education." The EACE Objectives are:

- To improve interaction among policy makers, educators, and those involved in the continuum of care of patients with cancer

- To support the translation of theoretical concepts into clinical care, for the benefit of patients, through research and education

- To provide training that enables individual educators and practitioners to:

-develop their practice using evidence-based approaches -identify their needs for personal and professional development

-develop the skills necessary for reflective practice -determine the effectiveness of their educational interventions

The third organization that comes together to collaborate at this annual meeting is the Cancer Patient Education Network (CPEN). The Cancer Patient Education Network is a group of Healthcare Professionals who share experiences and best practices in all aspects of cancer patient education. The overall mission of CPEN is to promote and provide models of excellence in patient, family, and community education across the continuum of care. CPEN works in collaboration with the National Cancer Institute's Office of Communication \& Education. A direct quote from a CPEN member says it all: "Learning about innovative programs and services has helped me improve the quality of patient education services at my center. CPEN has also helped me contribute to the development of patient education services at other centers."

When the American Society of Clinical Oncology (ASCO) and the American Association for Cancer Research (AACR) and other organization come together for their annual meetings, literally thousands of interested clinicians and scientists come together in what is euphemistically called "cancer week," and there is an amazing collection of brainpower assembled to consider how to make progress.

The coming together of the AACE, EACE, and CPEN could be called "cancer education week" and it assembles an amazing amount of talent and passion to improve education about cancer. I hope you'll be there!

This issue of the Journal of Cancer Education is a tribute to the work of cancer educators. It leads off with a minisymposium on oral cancer led by Drs Silverman and Vendrell Rankin. It has great information and is concisely assembled-please disseminate this widely to interested individuals. The other articles come from all over the globe. Read them, use them, form ideas about what you too can write to add to this field. With Springer's engine and all the goodness and quality in you, the practioners in the field, we can join together to really make a difference.

One year, we hosted Mr Fred Rogers of children's television fame as our graduation speaker at my institution, Dartmouth. There were some cries of discontent-why couldn't we have someone with more "gravitas" address the class instead of the host of Mr Rogers' Neighborhood. He went on to give a speech that was so memorable to all who were there - one of the best Commencement addresses I've ever heard, in fact. It was filled with stories ("the world isn't made of atoms - it's made of stories") and one story was particularly memorable to me and represents my vision of how we should work together in cancer education. $\mathrm{Mr}$ Rogers told the story of a Special Olympics event in the state of Washington. The hundred-yard dash began with the shot of the starting gun, but several yards into the race, one of the young participants, a boy with Downs syndrome, fell and began to cry. The other kids heard this, stopped running, and turned around to help him up. They then joined together and skipped to the finish line, and no one in that stadium witnessing that event could ever forget that image. That's how we should be doing our work together: helping each other up and joining together as a world community of cancer educators to cross the finish line. Remember that image! 